\section{Epidemics in English Villages}

IN his Milroy Lectures for 1942 before the Royal College of Physicians (Univ. Leeds Med. Magazine, 64 , 12 ; 1942) Dr. W. N. Pickles, the energetic medical officer of health for Aysgarth in Yorkshire, chose for his subject "Epidemic Disease in English Village Life in Peace and War". He makes a strong appeal to country doctors to follow his example in keeping diligent records, preferably in chart form, of various epidemics in their districts such as influenza, scarlet fever, measles, German measles, mumps, acute rheumatism and cholera, summer diarrhœe, epidemic jaundice and epidemic myalgia, the last being a disease which Dr. Pickles was one of the first in Great Britain to describe. Contrary to what he had expected, Dr. Pickles has so far not found that war conditions have caused an increase of epidemic disease, although village life has changed to some extent owing to the immigration of town children. Since the outbreak of the War there has been no scarlet fever or infantile paralysis in the Aysgarth district and only a few cases of measles and cerebrospinal fever, while the only epidemic due to an evacuee was one of jaundice, of which there were fourteen cases. The chief sources of annoyance were impetigo, vermin and scabies, but these were soon brought under control.

\section{Public Health Research}

According to an annotation in the Journal of the American Medical Association of July 25. the Health Research Institute of tho City of New York will receive a million dollars a year for ten years for researches on public health. The City and the Institute, which is a non-profit scientific institution, have entered into a contract which came into effect on July 1 and is automatically renewable for similar periods. The money is to be used to carry on fundamental medical research under the direction of a research council composed of authorities in medicine, biology, physiology, nutrition, public health and related subjects. Under the contract the services to be rendered by the Institute will include the following : (1) investigations into the control of diseases such as influenza, poliomyelitis, arthritis, degenerative diseases and general physiological problems; (2) engagement in laboratory experimentation in order to develop better and more economical biological products and improved technical procedures for use in controlling diseases and epidemics ; (3) aid to the director of the Bureau of Laboratories of the Depart. ment of Health in matters involving public health research.

\section{Electronic Relay Control}

$\mathrm{O}_{\mathrm{NE}}$ of the more useful by-products of the rapid development of radio technique is the use of thermionic valves as relays of negligible input power, freedom from contact troubles and practically instantaneous operation. These features are utilized to the full in the series of devices and instruments now marketed by Messrs. St'r Electronic Controls, 76 Cavendish Road, London, S.W.12, as the result of considerable experience. One of the devices comprises an electronic relay operating on the usual alternating current supply of 230 volts 50 cycles per second, and giving an output of either 200 or 1,000 watts, the latter being capable of starting a $\frac{1}{2}$ h.p. motor on 230 volts A.c. supply. This operation is obtained with no time delay and with an effective current through the regulating contacts of about two microamperes. The same instrument may also be used for high speed machine timing operations, or the regulation of temperature, pressure, humidity or hydraulic flow. As an example, a laboratory type of constant temperature bath is available, in which the accuracy of regulation is better than $\pm 0.01^{\circ} \mathrm{C}$. Another type is a liquid level regulator, with no float or other moving parts within the container; this is particularly suitable for use with electrolytes, and the electrodes may be a fraction of an inch apart or several feet from each other. An electronic 'stopwatch' records time intervals up to 2,000 seconds in intervals of a fifth of a second. It seems likely that these and other similar devices will find widespread application to laboratory and industrial processes.

\section{Ice on Conductors}

From time to time overhead lines fail by mechanical overstresses alone, due to excessive ice loading. These deposits have been widespread, and in view of the severity of recent winters, J. McCombe (Elec. Rev., Aug. 21) suggests that an amendment of the Electricity Commissioners' Overhead Line Regulations El. C. 53 (revised) is necessary. The suggestion is supported with the following observations and criticisms. In the first place the selection of a different basic loading for high-and low-voltage lines is very much open to criticism since wind and ice loading are functions of exposure and altitude and definitely not of line voltage or conductor size. Deposits on overhead lines in exposed places are more or less constant irrespective of voltage. If a better standard of construction is desired, then the more logical method would be to adopt a higher factor of safety of eroction. Low-voltage lines with the same ice coating will always have a greater security owing to the shorter span-length employed.

In the Regulations referred to, assumptions have been made to simplify the problem of ice loading. The ice is taken as forming a true annulus around the conductor. The author's observations are that ice is never deposited evenly or uniformly, either in wind or calm. Its nature depends to a great extent on the prevailing wind and atmosphere. In wind, ice tends to form thickest in the leeward side of the conductor. Windage helps to build up ice deposits, in as much that each particle of sleet imparts kinetic energy due to the wind and is responsible for the heavier deposits being driven to leeward. It probably also accounts for the different ice densities encountered on overhead lines. The worst deposits, however, are due to fog, not to wind and sleet. The heaviest deposits result from fog in the presence of a light wind, when icing is worst on the windward side of the conductor. It is thought that the fog precipitates ice as soon as it finds a metal anchorage. Such ice usually has a heavy, solid core, but becomes fuzzy and less dense on the surface. The article concludes with the suggestion that grading or zoning of the country, according to climatic conditions, would be advantageous, and by way of illustration describes the way this is done in the U.S.A.

\section{Recent Earthquakes}

Accomolng to the Swiss Seismological Bulletin for June 1942 just received from Zurich, twenty-one earthquakes were registered by the seismographs at 